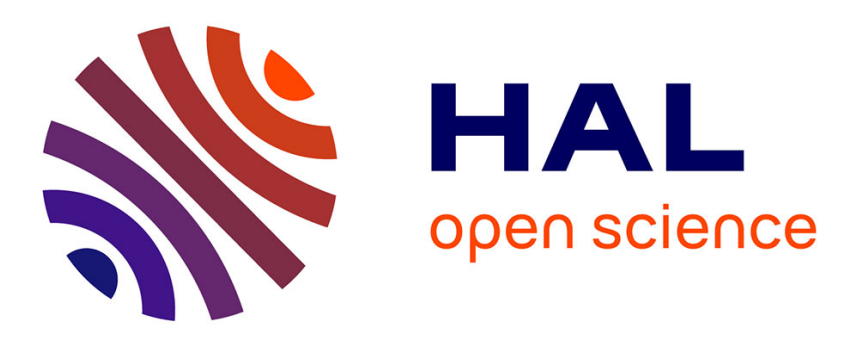

\title{
Novel access to verbenone via ruthenium nanoparticles-catalyzed oxidation of $A$-pinene in neat water
}

M. Rauchdi, M. Ait Ali, A. Roucoux, A. Denicourt-Nowicki

\section{- To cite this version:}

M. Rauchdi, M. Ait Ali, A. Roucoux, A. Denicourt-Nowicki. Novel access to verbenone via ruthenium nanoparticles-catalyzed oxidation of $A$-pinene in neat water. Applied Catalysis A : General, 2018, 550, pp.266-273. 10.1016/j.apcata.2017.11.016 . hal-01671613

HAL Id: hal-01671613

https://hal-univ-rennes1.archives-ouvertes.fr/hal-01671613

Submitted on 28 Feb 2018

HAL is a multi-disciplinary open access archive for the deposit and dissemination of scientific research documents, whether they are published or not. The documents may come from teaching and research institutions in France or abroad, or from public or private research centers.
L'archive ouverte pluridisciplinaire HAL, est destinée au dépôt et à la diffusion de documents scientifiques de niveau recherche, publiés ou non, émanant des établissements d'enseignement et de recherche français ou étrangers, des laboratoires publics ou privés. 


\section{Novel access to verbenone via ruthenium nanoparticles-catalyzed oxidation of $\alpha$-pinene in neat water.}

Mariem Rauchdi, a,b Mustapha Ait Ali, ${ }^{\text {, }}$ Alain Roucouxa and Audrey Denicourt-

$$
\text { Nowicki*a }
$$

a Ecole Nationale Supérieure de Chimie de Rennes, CNRS, UMR 6226, 11 Allée de Beaulieu, CS 50837, 35708 Rennes Cedex 7, France

b Équipe de Chimie de Coordination et de Catalyse, Département de Chimie, Université Cadi Ayyad, Faculté des Sciences Semlalia, BP 2390, Marrakech, Morocco

(*) Corresponding author: Audrey.Denicourt@ensc-rennes.fr

\section{Graphical abstract}

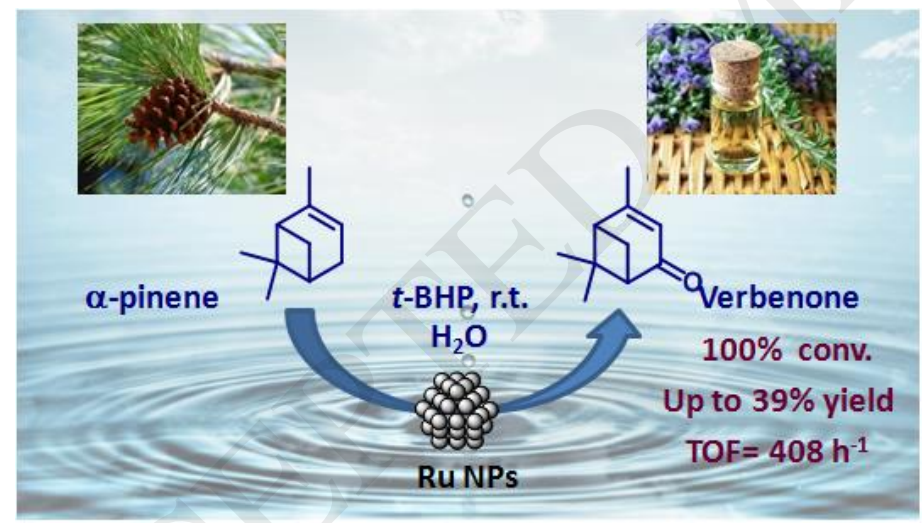

\section{Research Highlights}

- Ruthenium nanoparticles proved to be active in $\alpha$-pinene oxidation in neat water.

- An average yield towards verbenone of $41 \%$ was achieved.

- Radical species are involved in the allylic oxidation. 
- This catalytic process used eco-respectful reagent ( $t$-BHP) and solvent $\left(\mathrm{H}_{2} \mathrm{O}\right)$.

\begin{abstract}
Aqueous suspensions of $\mathrm{Ru}(0)$ nanoparticles, stabilized with hydroxyethylammonium salts and possessing sizes around $2 \mathrm{~nm}$, proved to be active and selective in the mild oxidation of $\alpha$-pinene in the presence of tert-butylhydroperoxide, in neat water. Verbenone, a product of great interest for fine chemistry, was obtained as major product with yield up to $41 \%$ under optimized conditions. 2-hydroxy-3-pinanone was identified as a co-product of the reaction, but with very low amount $(<7 \%)$. Kinetic investigations allowed determining the potential reaction intermediates and by-products. Moreover, mechanistic studies with radical scavengers confirmed that $\alpha$-pinene oxidation mainly implies both carbon- and oxygen-centered radicals.
\end{abstract}

\title{
Keywords
}

Ruthenium; Nanoparticles; Allylic oxidation; Terpenic olefins; Water; Sustainable processes

\section{Introduction}

The allylic oxidation of $\alpha$-pinene $\mathbf{1}$, a cheap biorenewable constituent of turpentine oil from pine plants, constitutes a great route for the synthesis of added-value verbenone 2 . This oxygenated compound is used in perfumery, aromatherapy and flavoring industry[1-2], as well as a key intermediate in the synthesis of therapeutic drugs, such as taxol [3]or potent antiischemic agents [4]. Recently, this enone has been reported to be an acetylcholinesterase inhibitor, thus presenting potential in early stage treatment of Alzheimer's disease[5]. Moreover, 
verbenone is also known as an anti-aggregation hormone, being registered as a biopesticide for the control of mountain pine beetles [6-7].

Verbenone could be found as a constituent of strawberry (traces detected in Ciflorette)[8], in vervain (20.5 wt.\%)[9], in Rosmarinus officinalis oils (27.0 - $28.9 \%$ )[10] and could also be obtained from biocatalytic approaches but with limited applications[11-13]. In that context, the design of selective allylic oxidation processes, using eco-responsible reagents and/or metal catalysts in non toxic solvents remains of great and challenging interest for improvement of productivity and selectivity [14]. In fact, during $\alpha$-pinene oxidation, two main competitive pathways could occur (Scheme 1), leading to the formation of verbenone $\mathbf{2}$ and verbenol $\mathbf{3}$ through allylic oxidation or pinene oxide 4 via the epoxidation of the cyclic double bond, according to the nature of the catalyst and/ or the stability of the radicals formed [15].

\section{- Scheme 1 -}

Up to now, various catalytic systems, either molecular complexes [16-20] or heterogeneous catalysts[21-32], have been used to produce verbenone. Nevertheless, in the most cases, low to medium yields were obtained (Figure 1) or most of these processes still suffer from various drawbacks, such as sophisticated catalytic systems, toxic organic solvents and high amounts of oxidants, long reaction times, and difficult catalyst's recovery.

\section{- Figure 1 -}

In the last decades, metallic nanoparticles have attracted considerable attention as highly active and eco-responsible catalysts for many processes such as hydrogenation, carboncarbon coupling as well as in oxidation reactions[33]. To our knowledge, only few reports are related to the use of nanoscale catalysts for the oxidation of $\alpha$-pinene. Nanosized $\mathrm{Co}_{3} \mathrm{O}_{4}$ particles proved to be efficient for the epoxidation of this terpenic olefin with air and $t$-BHP as initiator in DMF[34], while bimetallic $\mathrm{AuCu}$ nanoparticles deposited on $\mathrm{TiO}_{2}$ favored the formation of 
verbenone with $t$-BHP in acetonitrile [30]. Finally, in the context of promising technologies development, the use of cleaner solvents as replacement of usual organic solvents also contributes to the efforts towards more eco-respectful oxidation processes [35]. For instance, water has paid great attention, being inexpensive and environmentally benign and affording unique reactivity and selectivity[36-37].

Herein, we report the use of aqueous suspensions of ruthenium(0) nanoparticles as an alternative catalyst for the liquid-phase allylic oxidation of $\alpha$-pinene into verbenone, in water as a suitable industrial green solvent[38]. In this study, ammonium surfactants, well-known in our team, were used as capping agents of the ruthenium nanospecies, thus providing relevant micellar nanoreactors for catalytic applications under biphasic liquid-liquid conditions [39-40]. Moreover, $\mathrm{N}$-oxides were evaluated as an alternative and original family of stabilizers, presenting the advantages to be highly water-soluble and stable under oxidative conditions. After optimization of the reaction conditions, kinetic and mechanistic investigations have been performed to identify the various intermediates, as well as the reactive species, in this oxidation reaction. This novel and eco-compatible process, using nanosized catalytic species in neat water, could constitute an important technological and environmental breakthrough, for the valorization of biorenewable resources.

\section{Experimental}

\subsection{Materials and Methods.}

Ruthenium(III) trichloride hydrate $\left(\mathrm{RuCl}_{3} \cdot 3 \mathrm{H}_{2} \mathrm{O}\right)$ was obtained from Strem Chemicals. All commercially available organic compounds, polyvinylpyrrolidinone (PVP; M. W. $=40000)$ and the $70 \% \mathrm{w} / \mathrm{w}$ aqueous tert-butylhydroperoxide (Luperox ${ }^{\circledR}$ TBH70X) were purchased from Aldrich or Acros and used without further purification. Water was distilled twice by 
conventional method, before use. The ammonium surfactants (HEA16Cl, HEA16Br, HEA16BF 4 ) were synthesized from already published procedure[40], as well as THEA16Cl [41].

\subsection{Synthesis of $\mathrm{N}$-Oxide (NO) derivatives}

In a $100 \mathrm{~mL}$ round bottom flask equipped with a condenser and a dropping funnel, $2.5 \mathrm{~mL}$ (7.5 mmol) dimethylalkylamine were introduced in methanol $(10 \mathrm{~mL})$. The reaction mixture was refluxed for one hour, and $1.15 \mathrm{~mL}(11.25 \mathrm{mmol}, 1.5 \mathrm{eq})$ of hydrogen peroxide (30 wt. \%) was added dropwise. The reaction was heated at $70^{\circ} \mathrm{C}$ under vigorous stirring for $15 \mathrm{~h}$, and was followed by Thin Layer Chromatography. The solvent was removed and the product was dried in a lyophilizer for $24 \mathrm{~h}$.

N012 (dimethyldodecylamine oxide): White solid, 96\% yield, $\mathrm{R}_{\mathrm{f}}=0,65$ (AcOEt), NMR ${ }^{1} \mathrm{H}(400$ $\left.\mathrm{MHz}, \mathrm{CDCl}_{3}, 25^{\circ} \mathrm{C}, \mathrm{TMS}\right): \delta=0.81(\mathrm{t}, 3 \mathrm{H}), 1.19(\mathrm{~m}, 16 \mathrm{H}), 1.27(\mathrm{~m}, 2 \mathrm{H}), 1.79(\mathrm{~m}, 2 \mathrm{H}), 3.14(\mathrm{~s}, 6 \mathrm{H})$, $3.20(\mathrm{~m}, 2 \mathrm{H})$; $\mathrm{NMR}{ }^{13} \mathrm{C}\left(100 \mathrm{MHz}, \mathrm{CDCl}_{3}, 25^{\circ} \mathrm{C}, \mathrm{TMS}\right): \delta=14.09,22.65,23.94,26.64,29.29-$ $29.56,31.87,58.30,71.74, \mathrm{~T}_{\mathrm{f}}=120^{\circ} \mathrm{C}$.

N016 (dimethylhexadecylamine oxide): White solid, 97\% yield, $\mathrm{NMR}^{1} \mathrm{H}\left(400 \mathrm{MHz}, \mathrm{CDCl}_{3}, 25^{\circ} \mathrm{C}\right.$, TMS): $\delta=0.81(\mathrm{t}, 3 \mathrm{H}), 1.19(\mathrm{~m}, 24 \mathrm{H}), 1.27(\mathrm{~m}, 2 \mathrm{H}), 1.79(\mathrm{~m}, 2 \mathrm{H}), 3.13(\mathrm{~s}, 6 \mathrm{H}), 3.20(\mathrm{~m}, 2 \mathrm{H})$; NMR ${ }^{13} \mathrm{C}\left(100 \mathrm{MHz}, \mathrm{CDCl}_{3}, 25^{\circ} \mathrm{C}, \mathrm{TMS}\right): \delta=14.10,22.67,23,93,26.64,29.30-29.67,31.90,58.31$, 71.72.; $\mathrm{T}_{\mathrm{f}}=98^{\circ} \mathrm{C}$.

\subsection{Synthesis of the aqueous ruthenium (0) suspension}

The suspension was prepared at ambient temperature $\left(20^{\circ} \mathrm{C}\right)$. The procedure was similar for all ammonium and $N$-oxide protective agents.

An aqueous solution of the appropriate surfactant ( $7.6 \times 10^{-5}$ mol, 2 eq.) in $4 \mathrm{~mL} \mathrm{of} \mathrm{H}_{2} \mathrm{O}$, was added to $3.6 \mathrm{mg}$ of sodium borohydride $\left(9.5 \times 10^{-5} \mathrm{~mol}, 2.5\right.$ eq) in $2 \mathrm{~mL} \mathrm{H}_{2} \mathrm{O}$. Then this solution was quickly added under vigorous stirring to an aqueous solution (4 mL) of $\mathrm{RuCl}_{3} .3 \mathrm{H}_{2} \mathrm{O}$ 
precursor (10 mg, $\left.3.8 \times 10^{-5} \mathrm{~mol}, 1 \mathrm{eq}\right)$ to obtain $10 \mathrm{~mL}$ of an aqueous suspension of $\mathrm{Ru}(0)$ nanoparticles. The reduction, characterized by a color change from yellow-brown to black, is instantaneous and the obtained colloidal suspensions are stable for several weeks.

The aqueous Ru@PVP suspension was synthesized according to the procedure previously described by Hirai.

\subsection{General procedure of allylic oxidation of $\alpha$-pinene and recycling experiments.}

In a $100 \mathrm{~mL}$ round bottom flask sealed with a septum, $5 \mathrm{~mL}\left(1.9 \times 10^{-5} \mathrm{~mol}, 1\right.$ eq. $)$ of aqueous ruthenium (0) suspension was introduced, as well as $258 \mathrm{mg}\left(1.9 \times 10^{-3} \mathrm{~mol}, 100\right.$ eq.) of $\alpha$ pinene. Then, the tert-butyl hydroperoxide solution $(70 \%)$ was added and the reaction mixture was stirred at ambient temperature $\left(20^{\circ} \mathrm{C}\right)$. At the end of the reaction, the product was extracted with $3 \times 3 \mathrm{~mL}$ cyclohexane/ ethylacetate (1/1), salted out with $\mathrm{NaCl}$ and dried with $\mathrm{MgSO}_{4}$. The conversion and the selectivity were determined by Gas Chromatography analysis, using octane as internal standard. The conversion was determined according to the amount of moles of $\alpha$ pinene consumed over the amount of moles of $\alpha$-pinene introduced in the reactor. The product yield was calculated according to the amount of moles of product formed over the amount of moles of substrate introduced in the reactor. The TurnOver Frequency (TOF) value determined at low conversion, was defined as mol of transformed substrate per mol of introduced Ru per hour and were determined by kinetic follow-up of the optimized reaction by extraction of small aliquots of the reaction medium over time. For recycling experiments performed at the end of the reaction, the product was extracted with $3 \times 3 \mathrm{~mL}$ cyclohexane/ ethylacetate (1/1). The aqueous suspension was easily separated by extraction and reused in a new run under similar reaction conditions.

\subsection{Analytical procedures}

Transmission Electron Microscopy (TEM) pictures were recorded on a JEOM TEM 100CXII electron microscope operated at an acceleration voltage of $100 \mathrm{kV}$. Samples were prepared by 
placing a drop of the suspension of ruthenium nanoparticles on a carbon-coated grid. Measurement of the size and number of particles was performed with an automatic counting program (Image J) using Microsoft Excel to generate histograms of size distribution, on the basis of 150 measured nanoparticles. Dynamic Light Scattering (DLS) experiments were carried out using a DelsaNano C instrument (Beckman Coulter) to determine the hydrodynamic size $D_{\mathrm{h}}$, as well as the zeta potential $\zeta$ of the colloidal suspensions, at room temperature. Gas chromatography (GC) analyses were run on a Trace GC Ultra (Thermo Scientific) gas chromatograph, equipped with a GC Restek RTx-5 capillary column (30 m, 0.32 i.d.) with He as carrier gas. The oven temperature was programmed from $40^{\circ} \mathrm{C}$ to $250^{\circ} \mathrm{C}$ at a rate of $10^{\circ} \mathrm{C} / \mathrm{min}$ with initial and final times of 2 and 5 min, respectively. The injector and detector temperatures were set at $250^{\circ} \mathrm{C}$. The identification of the main oxidation products was performed by comparison with commercial pure products and the quantification was performed using octane as internal standard.

\section{Results and Discussion}

\subsection{Influence of the protective agents.}

In an initial set of experiments, several protective agents of ruthenium(0) nanoparticles were screened to define the most suitable micellar nanoreactor (Figure 2) in terms of stability under the oxidative reaction conditions and catalytic performances. Six easily synthesized surfactants such as hydroxyethylammonium (HEA) derivatives with various counter-ions $(\mathrm{Cl}, \mathrm{Br}$, $\mathrm{BF}_{4}$ )[40], a trishydroxyethyl ammonium (THEA) surfactant [41] and N-oxide (NO12 and NO16) compounds, were used and compared with the commercially available CTABr surfactant and PVP (polyvinylpyrrolidinone) polymer. The aqueous suspensions of $\mathrm{Ru}(0)$ species were easily synthesized by chemical reduction of ruthenium chloride $\left(\mathrm{RuCl}_{3} .3 \mathrm{H}_{2} \mathrm{O}\right)$ with sodium borohydride, in the presence of the chosen stabilizing agent to avoid aggregation of the zerovalent nanoparticles. The screening was performed on the liquid-phase oxidation of $\alpha$ - 
pinene in water, at room temperature. The $70 \% \mathrm{w} / \mathrm{w}$ aqueous tert-butylhydroperoxide ( $t$-BHP) was selected as a suitable oxidant, owing to its higher safety and lower cost than anhydrous organic $t$-BHP solutions[42], as well its higher solubility in polar solvents than molecular oxygen or $\mathrm{H}_{2} \mathrm{O}_{2}$ [43]. Moreover, from an environmental point of view, this hydroperoxide generates tertbutanol as by-product, which could be easily recycled[44]. The results are gathered in Figure 2, based on the $\alpha$-pinene conversion, as well as the verbenone yield

\section{- Figure 2 -}

First, as a blank experiment, in the absence of ruthenium nanospecies, no oxidation products were detected, thus proving an expected catalyzed oxidation reaction. Whatever the protective agent is, good to complete conversions (from 89 to 100\%) were observed. In the HEA series, the counter-ion $\left(\mathrm{X}=\mathrm{Cl}, \mathrm{Br}, \mathrm{BF}_{4}\right)$ seems to slightly influence the selectivity towards the ketone in the following order: $\mathrm{Cl}>\mathrm{BF}_{4}>\mathrm{Br}$. In comparison, the reaction proceeds more slowly with the commercial CTABr surfactant with $89 \%$ conversion in the same reaction time (Figure 2, HEA16Br vs. CTABr). Finally, in the $N$-oxide series originally reported here as promising stabilizers, the derivative possessing a C12 lipoliphilic chain proves to be more efficient than NO16, with quite similar results than HEA16Cl.

Other oxidation products were also formed, but none in yields of $5 \%$ or greater, as frequently reported in the literature[18-19, 22]. 2-hydroxy-3-pinanone $\mathbf{5}$, which is known as a chiral auxiliary [45], was identified as the main co-product. Some of these minor products (See Supplementary Information) were identified by $\mathrm{NMR}{ }^{1} \mathrm{H}$ and ${ }^{13} \mathrm{C}$ analyses, and GC-MS investigations (Scheme 2), such as pinonic acid $\mathbf{6}$ and pinonic aldehyde 7. Both products have already been reported in the literature in the oxidation of $\alpha$-pinene using potassium permanganate[46].

- $\quad$ Scheme 2 -

\subsection{Influence of the $\mathrm{HEA16Cl}$ amounts.}


In a second set of experiments, $\mathrm{HEA} 16 \mathrm{Cl}$ was chosen as a relevant protective agent for the stabilization of $\mathrm{Ru}(0)$ nanospecies in neat water and the [HEA16Cl]/Ru ratio was optimized in the model reaction under standard conditions ( 3 equiv. $t$-BHP, $3 \mathrm{~h}$, room temperature). The results are gathered in Figure 3, in terms of conversion, yields of ketone 2 and 2-hydroxy-3pinanone 5.

- Figure 3 -

First, with one equivalent of protective agent, the ruthenium nanospecies were less stable and quickly aggregated under catalytic conditions. Finally, an optimum [HEA16Cl]/[Ru] ratio of 2 seems to be a good compromise to maintain efficiently the colloidal particles within the aqueous phase during the catalytic process and allow a relevant activity, combined with a good selectivity towards the ketone.

\subsection{Characterization of Ru $\mathbf{R}^{0} \mathrm{NPs}$.}

Transmission Electron Microscopy (TEM) of the easily prepared Ru@HEA16Cl nanocatalyst shows well-dispersed and near monodispersed particles with an average diameter of $2.25 \mathrm{~nm}$, as shown on the size distribution histogram (Figure 4). Around $76 \%$ of particles possess a size included between 2.0 and $2.5 \mathrm{~nm}$. The Dynamic Light Scattering (DLS) size analysis revealed that the ruthenium colloids coated with the HEA16Cl surfactant present a hydrodynamic size $D_{\mathrm{h}}$ around $15 \mathrm{~nm}$. Finally, from zeta potential value, measured by electrophoretic light scattering, the suspension has an apparent positive charge of $+39 \mathrm{mV}$, proving the efficient electrosteric stabilization of the ruthenium(0) particles by HEA16Cl through the combination of the lipophilic chain (steric protection) and the charged polar head (electrostatic effect).

- Figure 4 - 


\subsection{Optimization of the catalytic reaction}

After optimization of the catalyst, the oxidant ratio, as well as the addition technique, were optimized to achieve pertinent conversions and to limit the formation of co-product, using ruthenium(0) nanospecies stabilized with 2 equivalents of HEA16Cl (Table 1).

- Table 1 -

First, without $t$-BHP, no oxidation products were observed (Entry 1). In all other cases (Entries 2-6), verbenone $\mathbf{2}$ was identified as major product and 2-hydroxy-3-pinanone $\mathbf{5}$ as main co-product. The increase in $t$-BHP ratio from 1.5 to 3 equivalents (Entries 2-3) leads to a complete conversion, but with a slightly higher amount of co-product $\mathbf{5}$. Secondly, the addition of small amounts of oxidant at regular intervals $(1.0 \mathrm{~h})$ was studied, based on a global quantity of 3 equivalents of $t$-BHP (Entries 4-6). In all cases, the conversion was complete in $3 \mathrm{~h}$. However, through the addition of $2 \times 1.5$ eq. $t$-BHP (Entry 4), an optimum verbenone yield of $37 \%$ was achieved. In other cases (Entries 5-6), the lower amount of the ketone could be attributed to the formation of higher amounts of by-products, such as the ones resulting from skeletal rearrangement of $\alpha$-pinene derivatives under the reaction conditions[21, 47]. Hydrogen peroxide was tested under our conditions for comparison. Unfortunately, as already known in the literature,[48-50] ruthenium nanospecies catalyzed rapid and non productive decomposition of $\mathrm{H}_{2} \mathrm{O}_{2}$, and the dioxygen released had no major role in the oxidation process.

- Figure 5 -

The kinetics profile (Figure 5) indicates that a complete conversion of the substrate was achieved in one hour, with a 34\% yield in ketone. The TurnOver Frequency (TOF), calculated at the early stage of the reaction (5 minutes), was around $408 \mathrm{~h}^{-1}$ for the optimized reaction. Moreover, throughout the reaction, a very low amount of verbenol, which is more reactive towards oxidation than the $\alpha$-pinene, was observed as a co-product. In fact, under standard conditions, the verbenol is completely transformed into verbenone in 30 min (Scheme 3), as already reported in the literature[32]. 
- Scheme 3 -

The formation of 2-hydroxy-3-pinanone $5(<7 \%)$ could be attributed to the formation of low amounts of diol 8, followed by its oxidation into compound $\mathbf{5}$ (Scheme 4). To confirm this hypothesis, the oxidation of diol 8 with t-BHP ( 2 x 1.5 eq. $)$, in the presence of Ru@HEA16Cl as catalyst, leads to a $100 \%$ conversion, with a $32 \%$ yield in 2-hydroxy-3-pinanone $\mathbf{5}$. Nevertheless, at this stage of our investigations, we could not assume that the diol $\mathbf{8}$ is provided by ring opening of the epoxide, since the oxidation of the epoxide under optimized conditions did not lead to 5 .

- Scheme 4 -

The oxidation of $\alpha$-pinene has been performed with various temperatures using the optimized reaction conditions, to study the influence on the catalytic activity and the selectivity (Table 2, Entries 1-4). Best results in terms of conversion and selectivity were performed at room temperature (Table 2, Entry 1). In fact, a higher temperature of $60^{\circ} \mathrm{C}$ (Entry 2) leads to a decrease in selectivity, potentially due to formation of oligomerization-polymerization products as already reported in the literature.[18] In contrast, lowering the temperature up to $10^{\circ} \mathrm{C}$ (Entry 3) decreases the catalytic activity with $86 \%$ conversion in $3 \mathrm{~h}$, thus needing higher reaction time (Entry 4). Moreover, the influence of additional water in the reaction mixture (Table 2, Entries 5-7) has been studied, since some authors recently reported its promoting effect on the reaction rate in cyclohexane oxidation.[51] However, no beneficial effect of water addition has been observed in the oxidation of $\alpha$-pinene under optimized conditions. Moreover, the addition of a co-solvent, which could improve the solubility of the terpenic olefin, did not improve the results (Table 2, Entry 8).

- Table 2 - 
TEM imaging after catalysis revealed that the particles possess an unchanged size, around $2 \mathrm{~nm}$, with $84 \%$ of the nanoobjects between $1.75 \mathrm{~nm}$ and $2.25 \mathrm{~nm}$ (Figure 6). Moreover, the nanospecies could be easily recycled through a biphasic approach, by simple extraction. They proved to be active in the following run, with a complete conversion and a $37 \%$ yield in verbenone under similar conditions, thus validating the catalytic lifetime of the ruthenium particles.

- Figure 6 -

\subsection{Mechanistic investigations}

In order to demonstrate a probable radical type mechanism, the effects of radical traps were investigated in the ruthenium( 0 ) nanoparticles catalyzed oxidation of $\alpha$-pinene, using either oxygen radical scavengers (such as BHT or diphenylamine), as well as carbon radical trap (such as $\mathrm{CBrCl}_{3}$ ). First, the introduction after 5 min reaction of butylated hydroxytoluene (BHT), known as a radical scavenger for peroxy-radicals,[25] leads to a complete inhibition of the reaction with no more conversion (with a plateau around 33\%) and a decrease in the total ketone/alcohol yields (from $38 \%$ to $16 \%$ in $1 \mathrm{~h}$ ), as shown in Figure 7 . A similar trend was observed using diphenylamine, another oxygen radical trap. The use of $\mathrm{CBrCl}_{3}$, a carbon radical scavenger, leads to a marked inhibition of the products formation, confirming that the mechanism involved also carbon-centred radicals.

\section{- Figure 7 -}

\section{Conclusions}


In conclusion, verbenone, a value-added compound for flavorings industry or pharmaceuticals production, was synthesized with a 39\% yield through the valorization of $\alpha$ pinene, a biorenewable present in turpentine of pine trees. An eco-compatible allylic oxidation process was developed using easily prepared aqueous suspensions of ruthenium nanoparticles as catalyst, in the presence of $t$-BHP as a safe and quite environment-friendly oxidant and in water as a suitable safe industrial solvent. Kinetic and mechanistic investigations allowed to identify some of the intermediates formed, and to prove that radical species are likely to be involved in the oxidation reaction. This eco-respectful route under mild conditions to verbenone production may offer a promising alternative to the existing conventional processes.

\section{Acknowledgements}

The authors are grateful for the financial support offered by PHC-Toubkal program and Campus France (PHC Toubkal/15/14: 32462NF). Our thanks are also extended to Patricia Beaunier from Université Pierre et Marie Curie (Paris) for TEM experiments and Liege Oliviera Biesuz from Federal University of Rio Grande do Sul (UFRGS) for the synthesis of $\mathrm{N}$-oxide surfactants.

\section{Bibliographic References}

[1] B. Ali, N.A. Al-Wabel, S. Shams, A. Ahamad, S.A. Khan, F. Anwar, Asian Pac. J. Trop. Biomed. 5 (2015) 601-611.

[2] R. Agrawal, R. Joseph, J. Food Sci. Technol. 37 (2000) 430-432.

[3] P.A. Wender, T.P. Mucciaro, J. Am. Chem. Soc. 114 (1992) 5878-5879.

[4] C. Ju, S. Song, S. Hwang, C. Kim, M. Kim, J. Gu, Y.-K. Oh, K. Lee, J. Kwon, K. Lee, W.-K. Kim, Y. Choi, Bioorg. Med. Chem. Lett. 23 (2013) 5421-5425.

[5] D. Kaufmann, A.K. Dogra, M. Wink, J. Pharm. Pharmacol. 63 (2011) 1368-1371.

[6] C.J. Fettig, S.R. McKelvey, R.R. Borys, C.P. Dabney, S.M. Hamud, L.J. Nelson, S.J. Seybold, J. Econ. Entomol. 102 (2010) 1846-1858.

[7] R.T. Carde, A.K. Minks, Insect Pheromone Research New Directions, Springer, 1997.

[8] R.J. Cannon, D. Agyemang, N.L. Curto, A. Yusuf, M.Z. Chen, A.J. Janczuk, Flavour Frag. J. 30 (2015) 302-319.

[9] M. Shamsardakani, M. Mosaddegh, A. Shafaati, Iran. J. Pharm.l Res. Volume 2 (2010) 39-

42.

[10] U. Ravid, E. Putievsky, I. Katzir, E. Lewinsohn, N. Dudai, Flavour Frag. J. 12 (1997) 109112. 
[11] K.A.C. Vespermann, B.N. Paulino, M.C.S. Barcelos, M.G. Pessôa, G.M. Pastore, G. Molina, Appl. Microbiol. Biotechnol. 101 (2017) 1805-1817.

[12] A. Negoi, V.I. Parvulescu, M. Tudorache, Catal. Today (2017).

[13] T. Vanek, J. HalíK, R. VankovÁ, I. ValterovÁ, Biosci., Biotechnol. Biochem. 69 (2005) 321-

325.

[14] E.F. Murphy, T. Mallat, A. Baiker, Catal. Today 57 (2000) 115-126.

[15] U. Neuenschwander, F. Guignard, I. Hermans, ChemSusChem 3 (2010) 75-84.

[16] M. Islam, D. Hossain, P. Mondal, A.Singha Roy, S. Mondal, M. Mobarak, Bull. Kor. Chem. Soc. 31 (2010) 3765-3770.

[17] M. Lajunen, A.M.P. Koskinen, Tetrahedron Lett. 35 (1994) 4461-4464.

[18] N.V. Maksimchuk, M.S. Melgunov, Y.A. Chesalov, J. Mrowiec-Białoń, A.B. Jarzębski, O.A. Kholdeeva, J. Catal. 246 (2007) 241-248.

[19] M. Caovilla, A. Caovilla, S.B.C. Pergher, M.C. Esmelindro, C. Fernandes, C. Dariva, K. Bernardo-Gusmão, E.G. Oestreicher, O.A.C. Antunes, Catal. Today 133-135 (2008) 695-698.

[20] J. Trissa, P. S. Dhanashree, C.S. Gopinath, S.B. Halligudi, J. Mol. Catal. A 184 (2002) 289299.

[21] P.A. Robles-Dutenhefner, B.B.N.S. Brandão, L.F. de Sousa, E.V. Gusevskaya, Appl. Catal. A: Gen. 399 (2011) 172-178.

[22] O.A. Kholdeeva, I.Y. Skobelev, I.D. Ivanchikova, K.A. Kovalenko, V.P. Fedin, A.B. Sorokin, Catal. Today 238 (2014) 54-61.

[23] I.Y. Skobelev, K.A. Kovalenko, V.P. Fedin, A.B. Sorokin, O.A. Kholdeeva, Kinet. Catal. 54 (2013) 607-614.

[24] E.P. Romanenko, E.A. Taraban, A.V. Tkachev, Russ. Chem. Bull. 55 (2006) 993-998.

[25] J.-A. Becerra, L.-M. González, A.-L. Villa, J. Mol. Catal. A 423 (2016) 12-21.

[26] P. Selvam, V.M. Ravat, V. Krishna, J. Phys. Chem. C 115 (2011) 1922-1931.

[27] M. Selvaraj, M. Kandaswamy, D.W. Park, C.S. Ha, Catal. Today 158 (2010) 286-295.

[28] N.C. Desai, J.A. Chudasama, B.Y. Patel, K.A. Jadeja, T.J. Karkar, J.P. Mehta, D.R. Godhani, Microporous and Mesoporous Materials 242 (2017) 245-255.

[29] D.R. Godhani, H.D. Nakum, D.K. Parmar, J.P. Mehta, N.C. Desai, J. Mol. Catal. A 426, Part A (2017) 223-237.

[30] S. Ajaikumar, J. Ahlkvist, W. Larsson, A. Shchukarev, A.R. Leino, K. Kordas, J.P. Mikkola, Appl. Catal. A 392 (2011) 11-18.

[31] S.G. Casuscelli, G.A. Eimer, A. Canepa, A.C. Heredia, C.E. Poncio, M.E. Crivello, C.F. Perez, A. Aguilar, E.R. Herrero, Catal. Today 133-135 (2008) 678-683.

[32] P. Pal, S.K. Pahari, A.K. Giri, S. Pal, H.C. Bajaj, A.B. Panda, J. Mater. Chem. 1 (2013) 1025110258.

[33] D. Astruc (Ed.), Nanoparticles and Catalysis, Wiley-VCH Verlag GmbH \& Co. KGaA, Weinheim, 2008.

[34] J. Lei, X.-H. Lu, J.-L. Zhang, X.-L. Wei, D. Zhou, Q.-H. Xia, Indian J. Chem. 52A (2013) 709-

716.

[35] M. Cvjetko Bubalo, S. Vidović, I. Radojčić Redovniković, S. Jokić, J. Chem. Technol. Biotechnol. 90 (2015) 1631-1639.

[36] E. Genin, V. Michelet, in: Martine Poux, Patrick Cognet, C. Gourdon (Eds.), Green Process Engineering. From Concepts to Industrial Applications, CRC Press 2015, 2015, pp. 292-324.

[37] M.-O. Simon, C.-J. Li, Chem. Soc. Rev. 41 (2012) 1415-1427.

[38] D. Prat, A. Wells, J. Hayler, H. Sneddon, C.R. McElroy, S. Abou-Shehada, P.J. Dunn, Green Chem. 18 (2016) 288-296

[39] Audrey Denicourt-Nowicki, A. Roucoux, Chem.l Record 16 (2016) 2127-2141

[40] E. Guyonnet Bile, R. Sassine, A. Denicourt-Nowicki, F. Launay, A. Roucoux, Dalton Trans. 40 (2011) 6524-6531.

[41] C. Hubert, A. Denicourt-Nowicki, J.-P. Guegan, A. Roucoux, Dalton Trans. (2009) 73567358.

[42] E.C. McLaughlin, H. Choi, K. Wang, G. Chiou, M.P. Doyle, J. Org. Chem. 74 (2009) 730-738.

[43] R. Kumar, S. Sithambaram, S.L. Suib, J. Catal. 262 (2009) 304-313. 
[44] A. Corma, S. Iborra, A. Velty, Chem. Rev. 107 (2007) 2411-2502.

[45] V. Krishnamurthy, J.J. Landi, G.P. Roth, Synth. Commun. 27 (1997) 853-860.

[46] Masruri, M. Farid Rahman, B. Nurkam Ramadhan, IOP Conf. Ser.: Mater. Sci. Eng. 107 (2016).

[47] M.K. Lajunen, T. Maunula, A.M.P. Koskinen, Tetrahedron 56 (2000) 8167-8171.

[48] G. Barak, J. Dakka, Y. Sasson, J. Org. Chem. 53 (1988) 3553-3555.

[49] R. A. Sheldon, I. Arends, U. Hanefeld (Eds.), Green Chemistry and Catalysis, Wiley-VCH Verlag GmbH \& Co. KGaA, Weinheim, 2007.

[50] J.E. Bäckvall (Ed.), Modern Oxidation Methods, Wiley-VCH Verlag GmbH \& Co. KGaA, Weinheim, 2007.

[51] T.A. Fernandes, C.I.M. Santos, V. André, J. Kłak, M.V. Kirillova, A.M. Kirillov, Inorg. Chem. 55 (2016) 125-135. 


\section{Figures, schemes and tables captions}

Scheme 1. $\alpha$-pinene oxidation: Allylic oxidation vs. Epoxidation

Scheme 2. Identification of some co-products

Scheme 3. Rapid oxidation of verbenol into verbenone

Scheme 4. Plausible pathway for the formation of 2-hydroxy-3-pinanone 5

Figure 1. . An overview of the recent (2005-2017) literature concerning allylic oxidation of $\alpha$ pinene -Some relevant catalysts.

Figure 2. . Impact of various protective agents in the ruthenium-catalysed oxidation of $\alpha$-pinene in water. Reaction conditions: $\mathrm{Ru}$ nanocatalyst $\left(1.9 \times 10^{-5} \mathrm{~mol}\right), \alpha$-pinene $\left(1.9 \times 10^{-3} \mathrm{~mol}, 1\right.$ equiv.), $t$-BHP (5.7 x 10-3 mol, 3.0 eq.), $\mathrm{H}_{2} \mathrm{O}(5 \mathrm{~mL})$, ambient temperature $\left(20^{\circ} \mathrm{C}\right)$, $3 \mathrm{~h}$. Conversion and verbenone yield (\%) were determined by GC analysis using octane as internal standard. Conversions are mentioned in the green label.

Figure 3. Influence of the $\mathrm{HEA} 16 \mathrm{Cl}$ ratio on the stability and the catalytic activity in $\alpha$-pinene oxidation. Reaction conditions: Ru@HEA16Cl (1.9 x 10-5 mol), $\alpha$-pinene (1.9 x 10-3 mol, 1 equiv.), $t$-BHP (5.7 x $10^{-3} \mathrm{~mol}, 3.0$ eq.), $\mathrm{H}_{2} \mathrm{O}(5 \mathrm{~mL})$, ambient temperature $\left(20^{\circ} \mathrm{C}\right), 3 \mathrm{~h}$. Conversion and verbenone yield (\%) were determined by GC analysis using octane as internal standard. Conversions are mentioned in the green label.

Figure 4. Transmission Electron Microscopy (Scale Bar $=20 \mathrm{~nm}$ ) and Size Distribution of the optimized Ru@HEA16Cl catalytic system (150 nanoparticles measured).

Figure 5. Kinetics of Ru@HEA16Cl-catalyzed oxidation of $\alpha$-pinene. Reaction conditions: Ru@HEA16Cl (1.9 x 10-5 mol), $\alpha$-pinene ( 1.9 x 10-3 mol, 1 equiv.), $t$-BHP (5.7 x 10-3 mol, 3.0 eq.), $\mathrm{H}_{2} \mathrm{O}(5 \mathrm{~mL})$, ambient temperature $\left(20^{\circ} \mathrm{C}\right), 1 \mathrm{~h} 30$.

Figure 6. Transmission Electron Microscopy (Scale Bar = $20 \mathrm{~nm}$ ) and Size Distribution of the optimized Ru@HEA16Cl suspension after catalytic test (150 nanoparticles measured).

Figure 7. Kinetics of Ru@HEA16Cl-catalyzed oxidation of $\alpha$-pinene after addition of BHT. Reaction conditions: Ru@HEA16Cl (1.9 x 10-5 mol), $\alpha$-pinene $\left(1.9 \times 10^{-3} \mathrm{~mol}, 1\right.$ equiv.), $t$-BHP (5.7 x $10^{-3} \mathrm{~mol}, 3.0$ eq.), $\mathrm{H}_{2} \mathrm{O}(5 \mathrm{~mL})$, ambient temperature $\left(20^{\circ} \mathrm{C}\right), 1 \mathrm{~h} 00$ 
Table 1. Optimization of the oxidant ratio and addition on $\alpha$-pinene oxidation with Ru@HEA16Cl catalyst[a]

Table 2. Influence of the temperature and the dilution on Ru@HEA16Cl- catalysed oxidation of $\alpha$-pinene[a] 
Scheme 1.

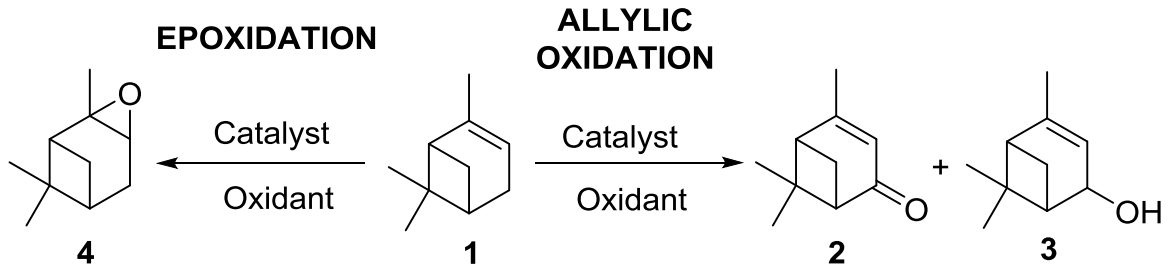

Figure 1.

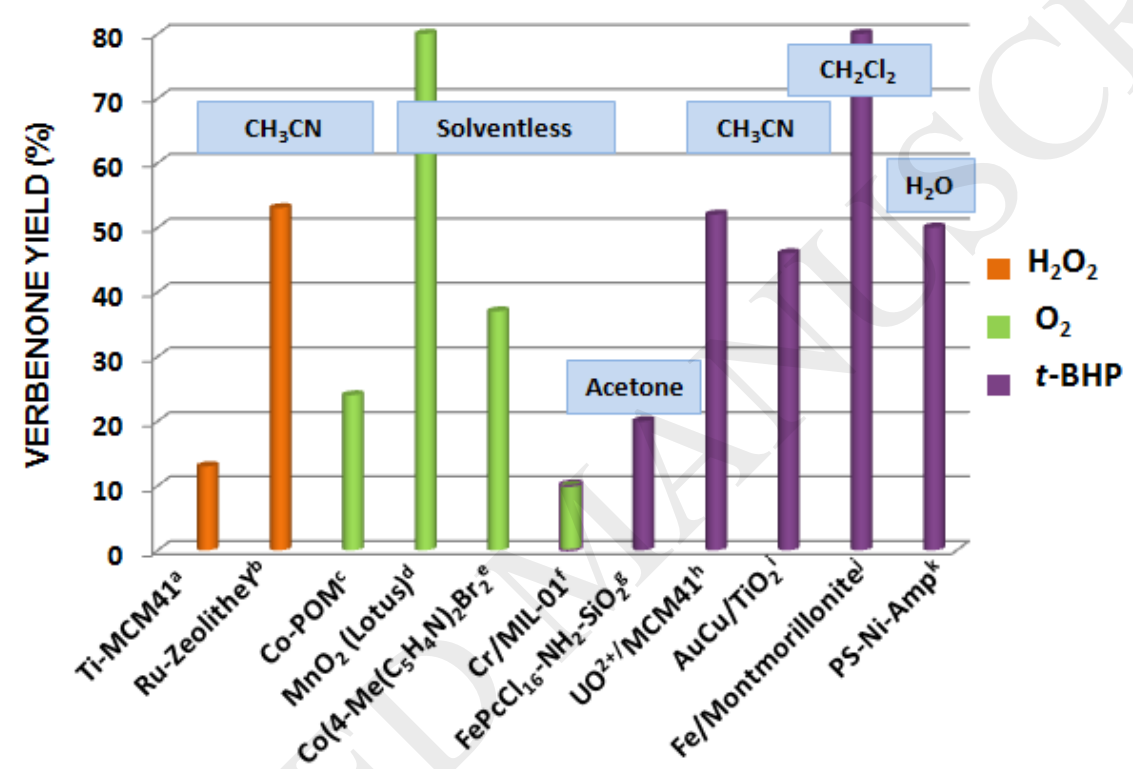

=Ti-MCM41 (1.12\%, w/w), $7 \mathrm{~h}, 70^{\circ} \mathrm{C}$, [ref. 31]

55 eq. $t$-BHP, $50^{\circ} \mathrm{C}, 3 \mathrm{~h}$, [ref. 25 ]

${ }^{b} \mathrm{Na}_{28.41}\left[\mathrm{Ru}_{053}(\mathrm{Ligand})_{0.45}\left(\mathrm{AlO}_{2}\right)_{30}\left(\mathrm{SiO}_{2}\right)_{162}\right], 18 \mathrm{~h}, 80^{\circ} \mathrm{C}$, [ref. 29] ${ }^{\mathrm{h}} 2 \mathrm{eq} . \mathrm{t}-\mathrm{BHP}, 70^{\circ} \mathrm{C}, 24 \mathrm{~h}$, [ref. 26$]$

c $[\mathrm{TBA}]_{4} \mathrm{H}\left[\mathrm{PW} \mathrm{W}_{11} \mathrm{Co}-\left(\mathrm{H}_{2} \mathrm{O}\right) \mathrm{O}_{39}\right], 1 \mathrm{~h}, 50^{\circ} \mathrm{C}$, [ref. 18] i 1 eq. $t$-BHP, $70^{\circ} \mathrm{C}, 24 \mathrm{~h}$, [ref. 30 ]

d 9 h, $75^{\circ} \mathrm{C}$, [ref. 32]

e 7 days, $72^{\circ} \mathrm{C}$, [ref. 17]

j 10 eq. $t$-BHP, $40^{\circ} \mathrm{C}, 50 \mathrm{~h}$ [ref. 24$]$

${ }^{f} \mathrm{O}_{2}+t$-BHP as initiator, $16 \mathrm{~h}, 60^{\circ} \mathrm{C}$, [ref. 22]

${ }^{k}$ eeq. $t$-BHP, $60^{\circ} \mathrm{C}, 8$ h, [ref. 16 ]

$\mathrm{POM}=$ PolyOxoMetallate $; \mathrm{PC}=$ PhthaloCyanine; $\mathrm{PS}=$ PolyStyrene; Amp $=$ Aminopyridine

Figure 2. 


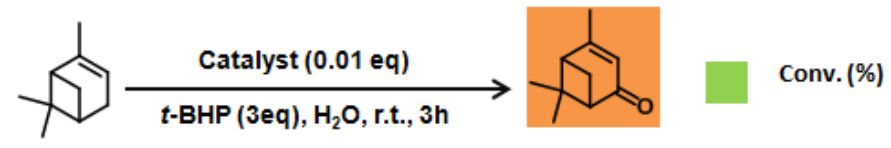<smiles>[X]C(=O)CN(C)CCO</smiles>

$\mathrm{X}=\mathrm{Cl}, \mathrm{HEA} 16 \mathrm{Cl}$

$\mathrm{X}=\mathrm{Br}, \mathrm{HEA} 16 \mathrm{Br}$

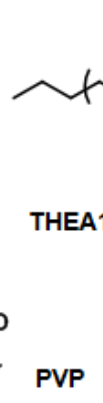

\section{$\mathrm{OH}$}

$\mathrm{X}=\mathrm{BF}_{4}, \mathrm{HEA}_{16 \mathrm{BF}}$<smiles>CC(C)(C)C(N1CCCC1=O)C(C)(C)C</smiles><smiles>CCCCCN(C)CCCC</smiles>

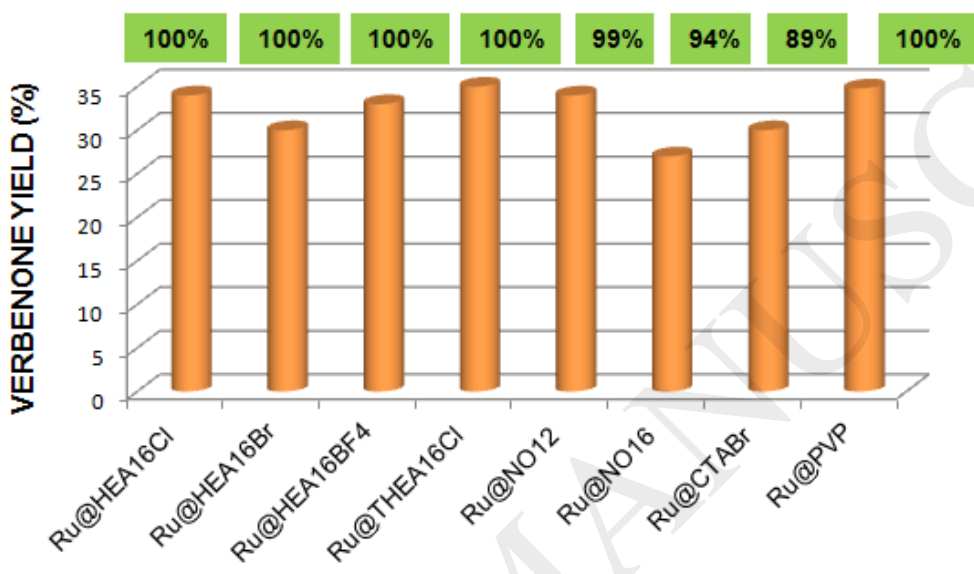

$\mathrm{HEA}=$ HydroxyEthylAmmonium, $\mathrm{THEA}=$ TrisHydroxyEthylAmmonium, $\mathrm{NO}=\mathrm{N}$-Oxide, $\mathrm{CTABr}=$ CetylTrimethylAmmonium Bromide, $\mathrm{PVP}=$ PolyVinylPyrrolidinone

Scheme 2 .<smiles>CC1(C)CC2(O)C(=O)CC1(C)C(C)(C)C2(C)C</smiles><smiles>CC(=O)C1CC(CC(=O)O)C1(C)C</smiles><smiles>[3H]CC1CC(C=O)C1(C)C</smiles> 
Figure 3.

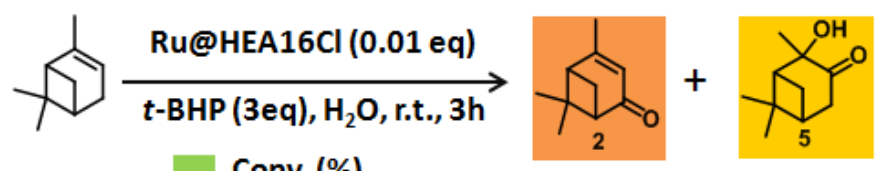

Conv. (\%)

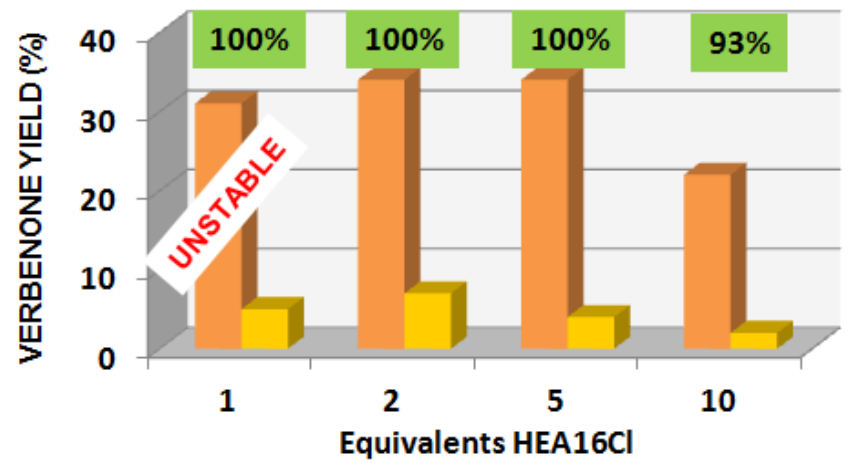

Figure 4.

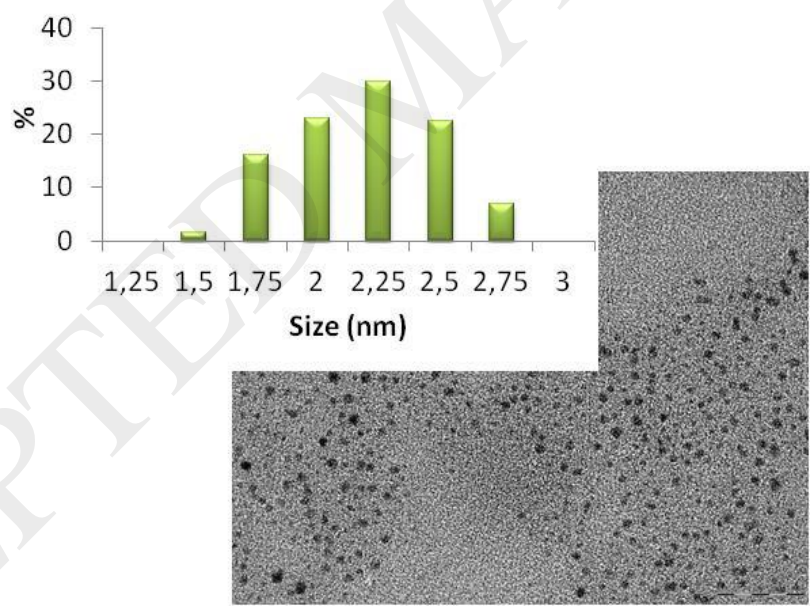

Figure 5. 


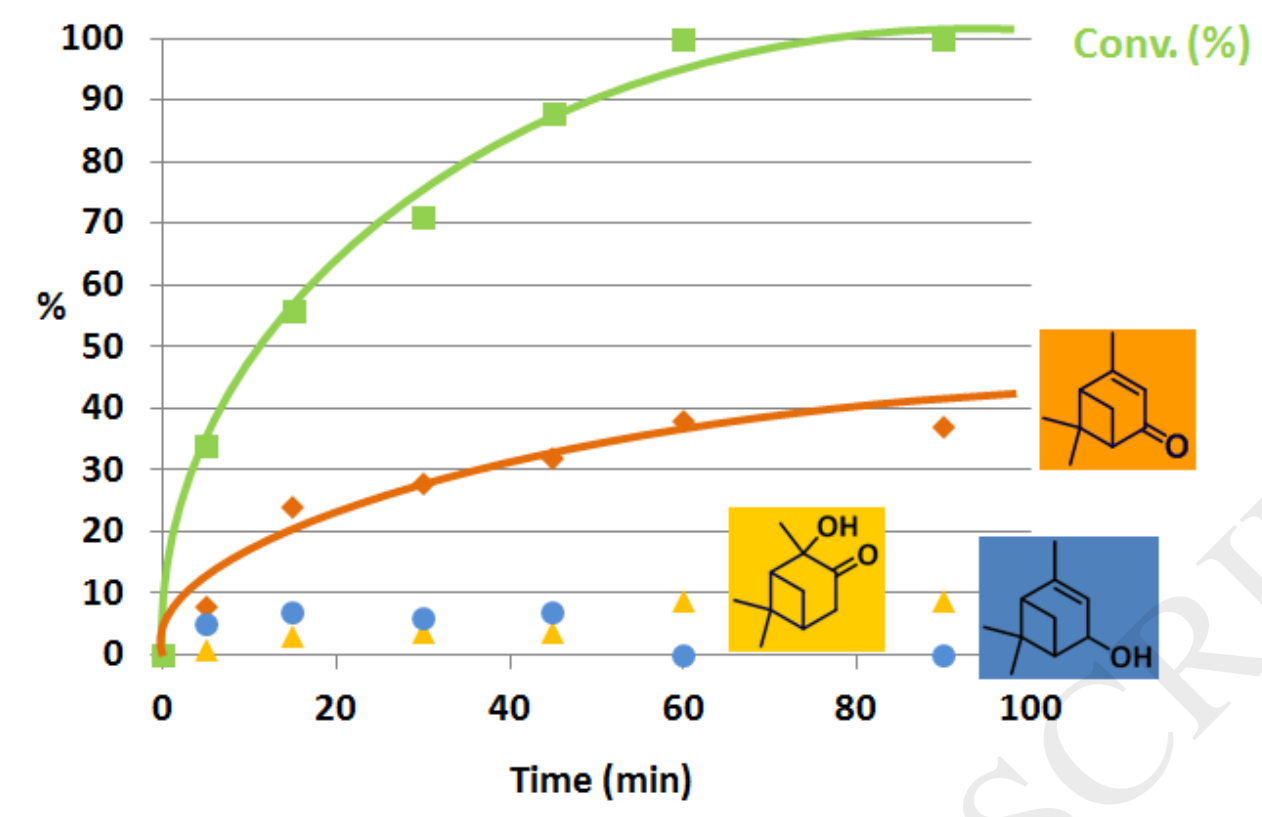

Scheme 3.

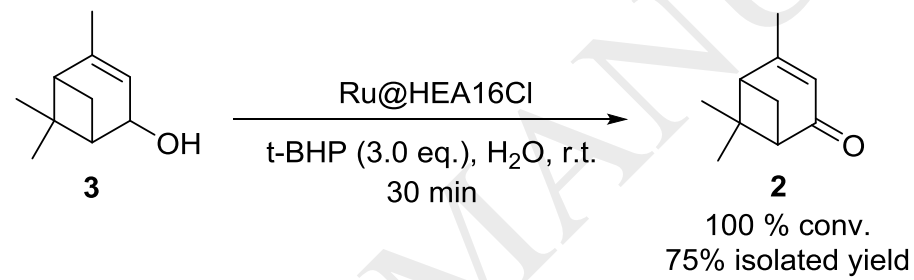

Scheme 4 .<smiles>CC1(C)C2CC(O)C(C)(O)C1C2</smiles>

8

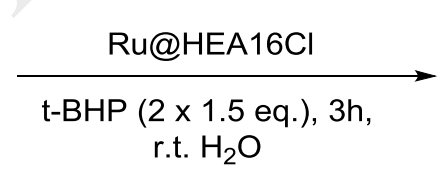

$100 \%$ conv.<smiles>CC1(C)CC2(C)CCC1C(=O)C2(C)O</smiles>

$32 \%$ yield 
Figure 6.

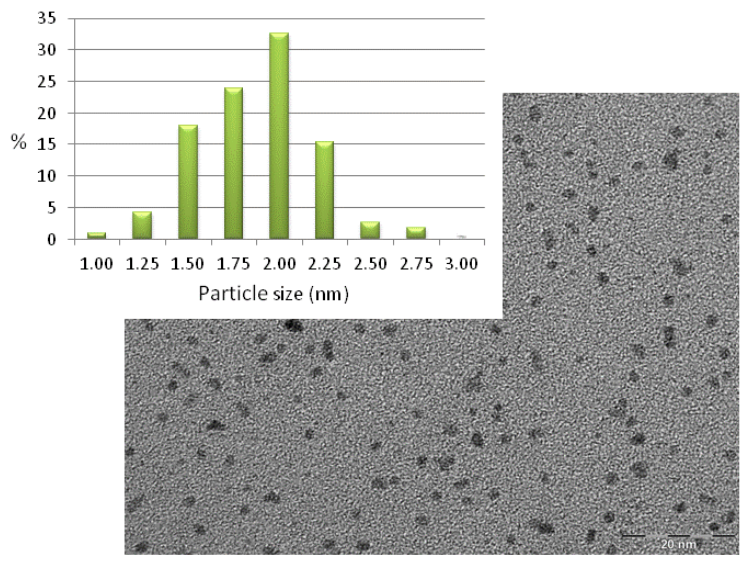

Figure 7.

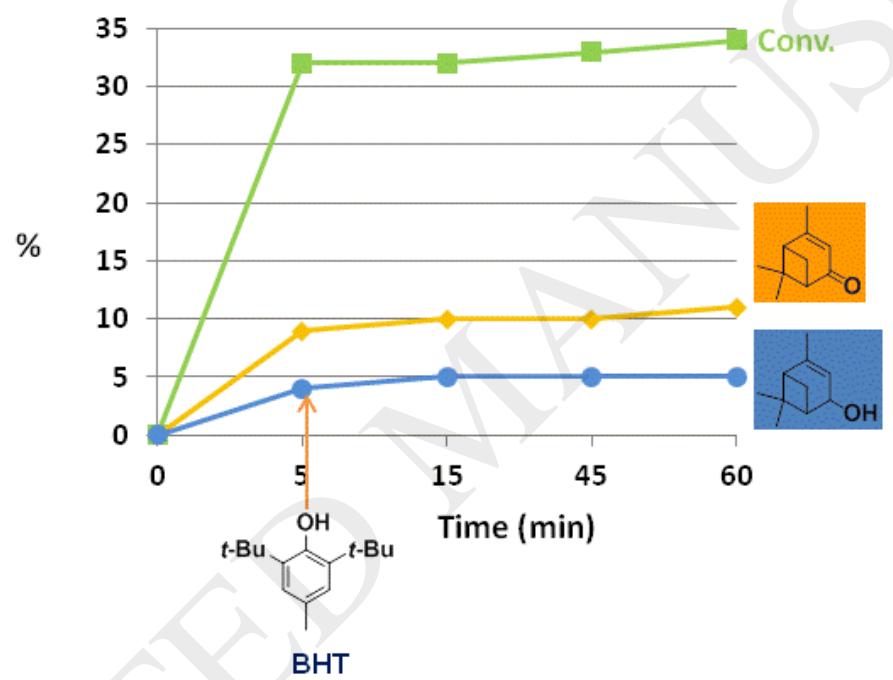


Table 1.

\begin{tabular}{|c|c|c|c|c|c|}
\hline & & $\frac{\mathrm{Ru} @ \mathrm{HEA} 16}{t \text {-BHP, } \mathrm{H}_{2} \mathrm{O}, \mathrm{r} .}$ & 2 & 5 & \\
\hline Entry & $\begin{array}{c}\text { Oxidant } \\
\text { ratio }\end{array}$ & Conversion $[\mathrm{d}](\%)$ & $\begin{array}{l}\text { Verbenone } \\
\text { yield [d] (\%) }\end{array}$ & $\begin{array}{c}5 \text { yield }[\mathrm{d}] \\
(\%)\end{array}$ & $\begin{array}{l}\text { Yield in other } \\
\text { products (\%) }\end{array}$ \\
\hline $1^{[a]}$ & 0 & 0 & 0 & 0 & 0 \\
\hline $2^{[\mathrm{a}]}$ & 1.5 & 75 & 34 & 2 & 39 \\
\hline $3[\mathrm{a}]$ & 3.0 & 100 & 34 & 7 & 59 \\
\hline $4^{[b]}$ & $2 \times 1.5$ & 100 & 39 & 6 & 55 \\
\hline $5^{[b]}$ & $3 \times 1.0$ & 100 & 29 & 3 & 68 \\
\hline $6[c]$ & $6 \times 0.5$ & 100 & 32 & 3 & 65 \\
\hline
\end{tabular}

[a] Reaction conditions: Ru@HEA16Cl (1.9 x 10-5 mol), $\alpha$-pinene (1.9 x 10-3 mol, 1 equiv.), $t$-BHP, $\mathrm{H}_{2} \mathrm{O}(5 \mathrm{~mL})$, ambient temperature $\left(20^{\circ} \mathrm{C}\right), 3 \mathrm{~h} .[\mathrm{b}]$ Reaction conditions: $\mathrm{Ru} @ \mathrm{HEA} 16 \mathrm{Cl}\left(1.9 \times 10^{-5}\right.$ mol), $\alpha$-pinene ( $1.9 \times 10^{-3}$ mol, 1 equiv.), $t$-BHP (3 equiv. in several times), $1 \mathrm{~h}$ per $t$-BHP addition, $\mathrm{H}_{2} \mathrm{O}(5 \mathrm{~mL})$, ambient temperature $\left(20^{\circ} \mathrm{C}\right), 3 \mathrm{~h}$ global reaction time. [c] Reaction conditions: Ru@HEA16Cl (1.9 x 10-5 mol), $\alpha$-pinene (1.9 x 10-3 mol, 1 equiv.), t-BHP (3 equiv. in several times), 30 min per $t$-BHP addition, $\mathrm{H}_{2} \mathrm{O}(5 \mathrm{~mL})$, ambient temperature $\left(20^{\circ} \mathrm{C}\right), 3 \mathrm{~h}$ global reaction time. [d] Determined by GC analysis with octane as internal standard. 
Table 2.

\begin{tabular}{|c|c|c|c|c|c|c|}
\hline Entry & $\mathrm{T}\left({ }^{\circ} \mathrm{C}\right)$ & $\begin{array}{l}\text { Additional } \\
\mathrm{H}_{2} \mathrm{O}(\mathrm{mL})\end{array}$ & Conv.[b] (\%) & $\begin{array}{l}\text { Verbenone } \\
\text { yield }[\mathrm{b}](\%)\end{array}$ & $\begin{array}{c}5 \text { yield }[\mathrm{b}] \\
(\%)\end{array}$ & $\begin{array}{l}\text { Yield in other } \\
\text { products }(\%)\end{array}$ \\
\hline 1 & 20 & 0 & 100 & 39 & 6 & 55 \\
\hline 2 & 60 & 0 & 100 & 29 & 3 & 68 \\
\hline $3^{[c]}$ & 10 & 0 & 86 & 31 & 3 & 52 \\
\hline $4[\mathrm{~d}]$ & 10 & 0 & 97 & 33 & 4 & 60 \\
\hline 5 & 20 & 2.5 & 97 & 38 & 4 & 55 \\
\hline 6 & 20 & 5.0 & 96 & 41 & 4 & 51 \\
\hline 7 & 20 & 7.5 & 97 & 39 & 0 & 58 \\
\hline $8^{[\mathrm{e}]}$ & 20 & 0 & 97 & 37 & 4 & 56 \\
\hline
\end{tabular}

[a] Reaction conditions: Ru@HEA16Cl (1.9 x 10-5 mol), $\alpha$-pinene (1.9 x 10-3 mol, 1 equiv.), $t$-BHP (5.7 x $10^{-3} \mathrm{~mol}, 2 \times 1.5$ eq.), $\mathrm{H}_{2} \mathrm{O}(5 \mathrm{~mL}), 3 \mathrm{~h}$. [b] Determined by GC analysis with octane as internal standard.

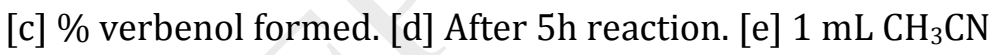

